\title{
Endobronchial Metastasis Of Ovarian Cancer: A Case Report And Literature Review
}

\section{Dong Rui Zhang}

Tianjin Chest Hospital https://orcid.org/0000-0003-0085-7533

\section{Li Yang}

Tianjin Chest Hospital

Wei Jia ( $\sim$ jiaweimr@126.com )

Tianjin Chest Hosptial

\section{Case report}

Keywords: ovarian cancer, endobronchial metastasis, diagnosis, prognosis

Posted Date: July 20th, 2020

DOI: https://doi.org/10.21203/rs.3.rs-42710/v1

License: (c) This work is licensed under a Creative Commons Attribution 4.0 International License. Read Full License 


\section{Abstract}

Background: Metastasis to the endobronchial from primary ovarian carcinoma (OC) is very rare. To enhance our understanding of this disease, we report a case of endobronchial metastasis from primary $\mathrm{OC}$ and review the literature.

Case presentation: This is a case report and retrospective analysis of bronchial tumor patient secondary form primary OC. The patient was a 51-year-old woman who presented intermittent cough and expectoration for 3 month, and suffocating pneumonia for 3 weeks. Multiple nodular masses at the right upper lobe and thickening soft tissue with surrounding invasion of bronchi at the left upper lobe were found. The chest $X$ ray scan demonstrated that enlarged right and left upper hilar, spreading mediastinum, elevated right septum were observed. Bronchoscopy showed that stenosis of the opening of right main bronchus and apical, middle and posterior segmental bronchi at right lobe was identified and the opening of left main bronchus was almost completely blocked by some visible neoplasm. The pathological result indicated that the disease was bronchial tumor derived from primary $\mathrm{OC}$. Until now, only 12 cases were reported. The latent period ranged from 2 months to 21 years and the overall survival time ranged from 1.5 months to 5.5 years.

Conclusions: The endobronchial is one of metastasis site of OC. The latent period of the disease is long and after active treatment, good prognosis can be acquired. This is the first study on endobronchial metastasis from primary OC, in China.

\section{Introduction}

Ovarian cancer $(\mathrm{OC})$ is considered as the most lethal gynecologic malignancy for the highest mortality and the absence of specific symptoms at the early stage [1]. The endobronchial metastasis from primary $\mathrm{OC}$ is extremely rare in clinical. From the first case of endobronchial metastasis from primary OC reported by Westerman in 1980, there are only 12 reported cases until now [2]. Since the latent period is long and the clinical characteristics are atypical, it is difficult to distinguish it from the primary bronchial tumor. Here, we report a case of endobronchial metastasis from primary OC.

\section{Case Report}

A 51-year-old female patient showed intermittent cough and expectoration for 3 month and suffocating pneumonia for 3 weeks. The patient presented chest tightness, back pain on the right side, weakness, night sweats during the examination in the 3 months prior to admission. Besides, multiple nodular masses at the right upper lobe, thickening soft tissue with surrounding invasion of bronchi at the left upper lobe, enlargement of the bilateral hilar and mediastinal lymph nodes were found by the chest computed tomography (CT) scan. The patient showed intensive suffocating pneumonia, blood-stained sputum, legs edema at 3 days before admission. The treatment of moxifloxacin combined with doxofylline and hydrocortisone didn't relieve her cough. Therefore, the patient was admitted to our hospital in Nov.2018.

Due to the OC, the patient was treated by taxol and oxaliplatin for 1 cycle of chemotherapy. Then, the patient was conducted resection of ovarian, uterus, greater omentum and lymph nodes on the left clavicle in Aug. 2016. After the resection, the patient was treated by taxol and oxaliplatin for 5 cycles of chemotherapy and next, by irinotecan and oxaliplatin for 5 cycles of chemotherapy, until Sep. 2017. After that, she has been taking traditional Chinese medicine for improvement.

On physical examination, she was conscious. Her abdomen was flat and soft, and there was no tenderness. She had clubbing fingers and legs edema. The carcinoembryonic antigen levels in serum were increased and her other indexes in routine testing were listed in Table 1. The chest $X$ ray scan showed that enlarged right and left upper hilar, spreading mediastinum, elevated right septum and multiple nodular masses at the right upper lobe were observed (Fig. 1). To differentiate primary tumor and metastasis, the flexible bronchoscopy was performed for her. The mucosa was congestive, edema and the tracheal carina was broadening (Fig. 2a). Granuloma was projected from the opening wall of right main bronchus (Fig .2b). Stenosis of the opening of right main bronchus and apical, middle and posterior segmental bronchi at right lobe was observed (Fig. 2c) and the opening of left main bronchus was almost completely blocked by some visible neoplasm (Fig. 2d). For the further observation, neoplasm was removed using clip and electric needle knife, and we saw the thickening and uneven mucosa. The hematoxylineosin (HE) staining of the neoplasm revealed that tumor cells arranged tightly and was irregular in shape (Fig. 3a). After

Page $2 / 9$ 
magnification, tumor cells and nucleus were not uniform in size and cells exhibited obvious atypia (Fig. 3b). The immunohistochemistry staining of the neoplasm showed anti-pan cytokeratin (CK) positivity in cytoplasm and anti-wilms tumor protein (WT-1) positivity in nucleus (Fig. 4a and b). Besides, the immunophenotypes of neoplasm were evaluated by antibodies to various makers and the results indicated that p53 were positively expressed and the rate of Ki-67 expression was more than $70 \%$ (Table 2). Integrating all above research, the pathological result was endobronchial tumor from primary OC. The patient didn't receive any chemotherapy for intolerance. Due to the terminal OC and multiple metastasis, the disease progresses fast. The patient abandoned treatment and died on 17 Dec. 2018.

The literature were searched from http://med.wanfangdata.com.cn and http://www.ncbi.nlm.nih.gov/pubmed. 11 papers published in English and no papers in Chinese reported 12 cases who suffered endobronchial metastasis from primary OC, until now (Table 3) [2-12]. The current patient was the $13^{\text {th }}$ one.

\section{Discussion And Conclusions}

$\mathrm{OC}$ is considered as the most lethal gynecologic malignancy and ovarian cancer cells can directly attack the surrounding pelvis organs such as bladder (17\%) and colon. Besides, ovarian cancer cells can also arrive at peritoneum and omentum (86\%), intestinal (50\%) and spleen (20\%), through peritoneal fluid transportation [13]. The common metastatic routes are lymphatic metastasis and direct invasion, while the hematogenous metastasis only accounts for $16 \%$ and the hematogenous metastatic sites are always liver, lung and pleura [13]. Although the end-stage OC can metastasize to lung, the endobronchial metastasis is extremely rare and there is no study on this disease in China, before our research. The intervals between primary OC and endobronchial metastasis are always long with the mean interval as 65.3 months, and the maximum time was up to 21 years [10]. The development of endobronchial metastasis from primary $\mathrm{OC}$ is a slow progress and the media survival time of 10 cases before 2018 ranged from 6 to 24 months [14]. Compared with metastatic chest tumors, the endobronchial metastasis from primary OC often showed good prognosis [15].

The potential mechanisms of endobronchial metastasis from primary OC were complicated and that may include mediastinal lymph nodes metastasis, hematogenous metastasis, lymphatic metastasis and parenchymal metastasis [7, 9, 16]. In addition, the routine imaging examination can't clearly distinguish endobronchial metastasis from primary bronchial tumors. Clinical manifestations of endobronchial metastasis are dyspnea, dry cough, hemoptysis, anhelation and hoarsness. However, 52\% $62.5 \%$ patients showed no respiratory symptoms [16]. Stenosis of airway and thickening vessel walls observed by chest CT, may be due to diseases from intratracheal site, tracheal mucosa and airway surroundings. Furthermore, only $50 \%$ endobronchial diseases can be found by chest CT. Therefore, physician scientists always misdiagnose the endobronchial metastasis from primary OC as primary bronchial tumors [3].

Flexible bronchoscopy is a direct detection method for endobronchial metastasis and its characteristics vary widely, including benllones combined with necrosis and nodular masses. However, flexible bronchoscopy can't differentiate between benign tumor, primary lung cancer and tumor metastasis. Therefore, pathological and immunohistochemistry assay are necessary to identify the tumor origins. According to the metastatic modes, the tumors metastasis to airways can be divided into four types, $\nabla$ type, direct metastatic tumor; $\Downarrow$ type, airway tumors invaded from pulmonary solid lesions; $\nabla$ type, airway tumors invaded from lymph nodes of mediastinum and hilum; $\nabla$ type, airway tumors invaded from peripheral lesions [17]. $\nabla$ and $\nabla$ types are in the majority. Dhillon et al reported a unique endobronchial metastasis combined with airway calcification [11]. Unfortunately, the clinical manifestations of airway calcification and broncholithiasis are very similar, which may result in misdiagnose. Ayub et al described an unusual endobronchial metastasis combined with aspergillosis and the patient showed hemoptysis [12].

The treatments for endobronchial metastasis, such as resection, chemotherapy and radiotherapy, depends on multiple aspects, like patients' status, age, and tumor size, location and others. Choi et al firstly reported that needle electrical knife was applied to remove the bronchial metastasis focuses and this method effectively relieved patients' dyspnea and hemoptysis [8]. The endobronchial intervention such as stent, local radiotherapy and photodynamic therapy, may be efficient methods for alleviating patients' dyspnea, hemoptysis and stenosis induced by endobronchial metastasis. However, endobronchial intervention showed little effect on patients with submucosa metastasis. Some research indicated that atomizing

Page 3/9 
chemotherapy might be an ideal method for patients with submucosa metastasis, for the long detention and high drug concentration in lesions, and it was estimated that the drug concentration in tumor tissues was almost $5 \sim 15$ times higher than that in normal lung tissues [16]. By now, some novel therapeutic regimens are still necessary for the treatment of endobronchial metastasis.

In conclusion, endobronchial metastasis from primary $\mathrm{OC}$ is extremely rare. The latent period of this disease was long and clinical manifestation are always hiding. Flexible bronchoscopy combined with imaging and immunohistochemistry tests are efficient diagnostic approach. Endobronchial intervention, radiotherapy and chemotherapy could be taken for the patients' treatment. The individual endobronchial metastasis can be acquired good prognosis after active treatment, while the prognosis of patients with multiple metastasis is usually poor.

\section{List Of Abbreviations}

OC: ovarian carcinoma;

CT: computed tomography scan

HE: hematoxylin-eosin staining

CK: cytokeratin (CK)

WT-1: wilms tumor protein 1

\section{Declarations}

\section{Ethics approval and consent to participate}

This research was approved by the Ethics Committee of the Tianjin Chest Hospital and the informed consent and medical record were obtained from the patients' family.

\section{Consent for publication}

The patient's medical record and individual data were consented to publish by the patients' family.

\section{Availability of data and materials}

All data generated or analyzed during this study are included in this published article.

\section{Competing interests}

The authors declare that they have no competing interests.

\section{Funding}

Not applicable

\section{Author contribution}

RZ and LY performed the chest X-ray, flexible bronchoscopy images, HE and Immunohistochemistry staining. RZ, LY and WJ analyzed and interpreted the patient's data. WJ wrote the manuscript and all authors read and approved the final manuscript.

\section{Acknowledgements}

Not applicable 


\section{References}

1. Brucks JA. Ovarian cancer. The most lethal gynecologic malignancy. Nurs Clin North Am. 1992;27:835-45.

2. Westerman DE, Urbanetti JS, Rudders RA, Fanburg BL. Metastatic endotracheal tumor from ovarian carcinoma. Chest. 1980;77(6):798-800.

3. Merrill CR, Hopkirk JA. Late endobronchial metastasis from ovarian tumor. Br J Dis Chest. 1982;6(3):253-4.

4. Merimsky O, Greif J, Chaitchik S, Inbar M. Endobronchial metastasis of ovarian cancer. A case report. Tumori. 1990;76(6):614-5.

5. Mateo F, Serur E, Smith PR. Bronchial metastases from ovarian carcinoma. Report of a case and review of the literature. Gynecol Oncol. 1992;46(2):235-8.

6. Wholey MH, Meyerrose GE, McGuire WP, Reinhardt MJ, Sostre S. Endobronchial lesion from metastatic ovarian carcinoma resulting in partial right mainstem obstruction demonstrated by lung scintigraphy. Clin Nucl Med. 1995;20(5):465-6.

7. Petru E, Friedrich G, Pickel H, Lax S, Beham A. Life-threatening tracheal metastasis complicating ovarian cancer-A case report. Gynecol Oncol. 1999;74(1):141-2.

8. Choi HS, Kim SY, Choi CW, You JH, Kang HM, Park MJ. Use of bronchoscopic electrocautery in removing an endotracheal metastasis. Lung Cancer. 2007;58(2):286-90.

9. Harrington A, Mahrer T, Chang D. A case of ovarian carcinoma with endobronchial metastases. Chest 2011; 140(4 Meeting Abstracts) 29A.

10. Upadhyay A, Goel V, Batra U, Goyal P, Dutta K, Aggarwal M, et al. Two cases of ovarian carcinoma with endobronchial metastases: Rare presentation. South Asian J Cancer. 2015;4(3):149.

11. Dhillon SS, Harris K, Pokharel S, Yendamuri S. Calcified Mediastinal Metastasis of Ovarian Cancer Mimicking Broncholithiasis. J Bronchol Intervent Pulmonol. 2016;23(3):229-31.

12. Ayub II, Thangaswamy D, Joseph LD, Meenakshisundaram M. Lung Parenchymal and Endobronchial Metastases from Ovarian Carcinoma. J Bronchol Intervent Pulmonol. 2018;25(3):235-8.

13. Kerr VE, Cadman E. Pulmonary metastases in ovarian cancer analysis of 357 patients. Cancer. 1985;56(5):1209-13.

14. Thomakos N, Diakosavvas M, Machairiotis N, Fasoulakis Z, Zarogoulidis P, Rodolakis A. Rare distant m metastatic disease of ovarian and peritoneal carcinomatosis: a review of the literature. Cancers. 2019;11(8):1044.

15. Danplat J, Hacker NF, Nieberg RK, Berek JS, Rose TP, Sagae S. Distant metastases in epithelial ovarian carcinoma. Cancer. 1987;60(7):1561-6.

16. Pickel H, Lahousen M, Stettner H, Girardi F. The spread of ovarian cancer. Balliere's Clin Obstet Gynaecol. 1989;3(1):3-12.

17. Kiryu T, Hoshi H, Matsui E, Iwata H, Kokubo M, Shimokawa K, et al. Endotracheal/endobronchial metastases: clinicopathologic study with special reference to developmental modes. Chest. 2001;119(3):768-75.

\section{Tables}

Table 1. Routine texting results of the patient in this study. 


\begin{tabular}{|c|c|c|c|}
\hline index & value & index & value \\
\hline \multicolumn{2}{|c|}{ Blood routine texting } & neu (\%) & $72.1 \%$ \\
\hline $\mathrm{Hb}$ & $126 \mathrm{~g} / \mathrm{L}$ & PLT & $337.00 \times 10^{9} \mathrm{~L}$ \\
\hline $\mathrm{Fg}$ & $5.35 \mathrm{~g} / \mathrm{L}$ & D-dimer & $1.00 \mu \mathrm{g} / \mathrm{mL}$ \\
\hline ESR & $49.0 \mathrm{~mm} / \mathrm{h}$ & WBC & $5.29 \times 10^{9} \mathrm{~L}$ \\
\hline \multicolumn{2}{|c|}{ Arterial blood gas } & $\mathrm{pH}$ & 7.472 \\
\hline $\mathrm{pCO}_{2}$ & $37.0 \mathrm{mmHg}$ & $\mathrm{pO}_{2}$ & $69.0 \mathrm{mmHg}$ \\
\hline $\mathrm{CHCO}_{3}^{-}$ & $27.4 \mathrm{mmol} / \mathrm{L}$ & $\mathrm{sO}_{2}$ & $94.7 \%$ \\
\hline $\mathrm{FiO}_{2}$ & $29.0 \%$ & & \\
\hline \multicolumn{2}{|c|}{ Tumor makers } & NSE & $58.07 \mathrm{ng} / \mathrm{mL}$ \\
\hline CYFRA21-1 & $18.57 \mathrm{ng} / \mathrm{mL}$ & CA125 & $86.82 \mathrm{U} / \mathrm{mL}$ \\
\hline \multicolumn{2}{|c|}{ Echocardiography } & $\mathrm{EF}$ & $56 \%$ \\
\hline PAP & $30 \mathrm{mmHg}$ & RVOT & $28 \mathrm{~mm}$ \\
\hline RVAW & $3 \mathrm{~mm}$ & & \\
\hline
\end{tabular}

Table 2 Immunohistochemistry results of the neoplasm from current patient.

\begin{tabular}{|llll|}
\hline antibody & Carcinomatous component & antibody & Carcinomatous component \\
\hline ER & - & PR & - \\
\hline WT- 1 & + & TTF-1 & - \\
\hline NapsinA & - & CD56 & - \\
\hline CK & + & P53 & + \\
\hline P40 & - & PAS & - \\
Ki-67 & $>70 \%$ & & \\
\hline
\end{tabular}

- = negative, + = positive

Table 3 Summary of endobronchial tumor from primary ovarian carcinoma. 


\begin{tabular}{|c|c|c|c|c|c|c|c|c|}
\hline \multirow[t]{2}{*}{ First Author } & \multirow[t]{2}{*}{ Age } & \multirow[t]{2}{*}{ type } & \multirow{2}{*}{$\begin{array}{l}\text { Time } \\
\text { (years) }\end{array}$} & \multirow{2}{*}{$\begin{array}{l}\text { Imaging } \\
\text { examination }\end{array}$} & \multirow{2}{*}{$\begin{array}{l}\text { Clinical } \\
\text { manifestations }\end{array}$} & \multirow[t]{2}{*}{ Therapy } & \multicolumn{2}{|l|}{ prognosis } \\
\hline & & & & & & & $\begin{array}{l}\text { Metastasis } \\
\text { to } \\
\text { other sites }\end{array}$ & $\begin{array}{l}\text { Survival } \\
\text { (months) }\end{array}$ \\
\hline Westerman $^{[2]}$ & 51 & PC & 7 & $\begin{array}{l}\text { Compact shadow } \\
\text { in trachea }\end{array}$ & dyspnea & Radiotherapy & NR & NR \\
\hline Merrill|[3] & 45 & $\mathrm{SCC}$ & 12 & $\begin{array}{l}\text { Compact shadow } \\
\text { in right middle } \\
\text { lobe }\end{array}$ & cough & $\begin{array}{l}\text { Right lower } \\
\text { lobe resection }\end{array}$ & NR & NR \\
\hline Merimsky ${ }^{[4]}$ & 83 & PA & 0.2 & $\begin{array}{l}\text { Airway } \\
\text { obstruction }\end{array}$ & dyspnea & Laser therapy & abdomen & 4 \\
\hline Mateo $^{[5]}$ & 62 & SA & 5 & $\begin{array}{l}\text { Bronchial } \\
\text { obstruction }\end{array}$ & $\begin{array}{l}\text { dyspnea, } \\
\text { cough }\end{array}$ & $\begin{array}{l}\text { Chemotherapy } \\
+ \\
\text { radiotherapy }\end{array}$ & brain & 22 \\
\hline Wholey[6] & 49 & NR & 2 & $\begin{array}{l}\text { Bronchial } \\
\text { obstruction }\end{array}$ & dyspnea & NR & NR & NR \\
\hline Petru $^{[7]}$ & 40 & SPA & 2.7 & lymphadenovarix & dyspnea & $\begin{array}{l}\text { Laser therapy } \\
+ \\
\text { Chemotherapy }\end{array}$ & NR & 6 \\
\hline Choi $^{[8]}$ & 33 & SPA & 7 & $\begin{array}{l}\text { Airway } \\
\text { obstruction }\end{array}$ & $\begin{array}{l}\text { dyspnea, } \\
\text { hemoptysis }\end{array}$ & $\begin{array}{l}\text { Chemotherapy } \\
+ \\
\text { radiotherapy }\end{array}$ & No & $>66$ \\
\hline Harrington $^{[9]}$ & 42 & SPA & 0.92 & $\begin{array}{l}\text { Right middle } \\
\text { lobe atelectasis }\end{array}$ & hemoptysis & $\begin{array}{l}\text { Chemotherapy } \\
+ \\
\text { radiotherapy } \\
\text { Chemotherapy } \\
+ \\
\text { radiotherapy }\end{array}$ & NR & NR \\
\hline Upadhyay[10] & 62 & SA & 21 & NR & $\begin{array}{l}\text { dyspnea, } \\
\text { cough }\end{array}$ & Chemotherapy & No & $>18$ \\
\hline Upadhyay[10] & 53 & SA & 6.3 & NR & $\begin{array}{l}\text { dyspnea, } \\
\text { cough }\end{array}$ & Intervention & NR & 18 \\
\hline Dhillon $^{[11]}$ & 61 & SPA & 12 & $\begin{array}{l}\text { Lymphadenovarix } \\
\text { and calcification }\end{array}$ & hemoptysis & $\begin{array}{l}\text { Radiotherapy } \\
\text { + laser } \\
\text { therapy }\end{array}$ & No & $>36$ \\
\hline Ayub ${ }^{[12]}$ & 22 & PA & 2 & $\begin{array}{l}\text { Bronchial } \\
\text { obstruction }\end{array}$ & hemoptysis & No & NR & 6 \\
\hline
\end{tabular}

$\mathrm{PC}=$ papillary cystadenocarcinoma, Time = time metastasis to $\mathrm{EC}, \mathrm{SCC}=$ serous cystadenocarcinoma, $\mathrm{PA}=$ papillary adenocarcinoma, NR = none reported, SPA = serous papillary adenocarcinoma, SA = serous adenocarcinoma,

Figures 


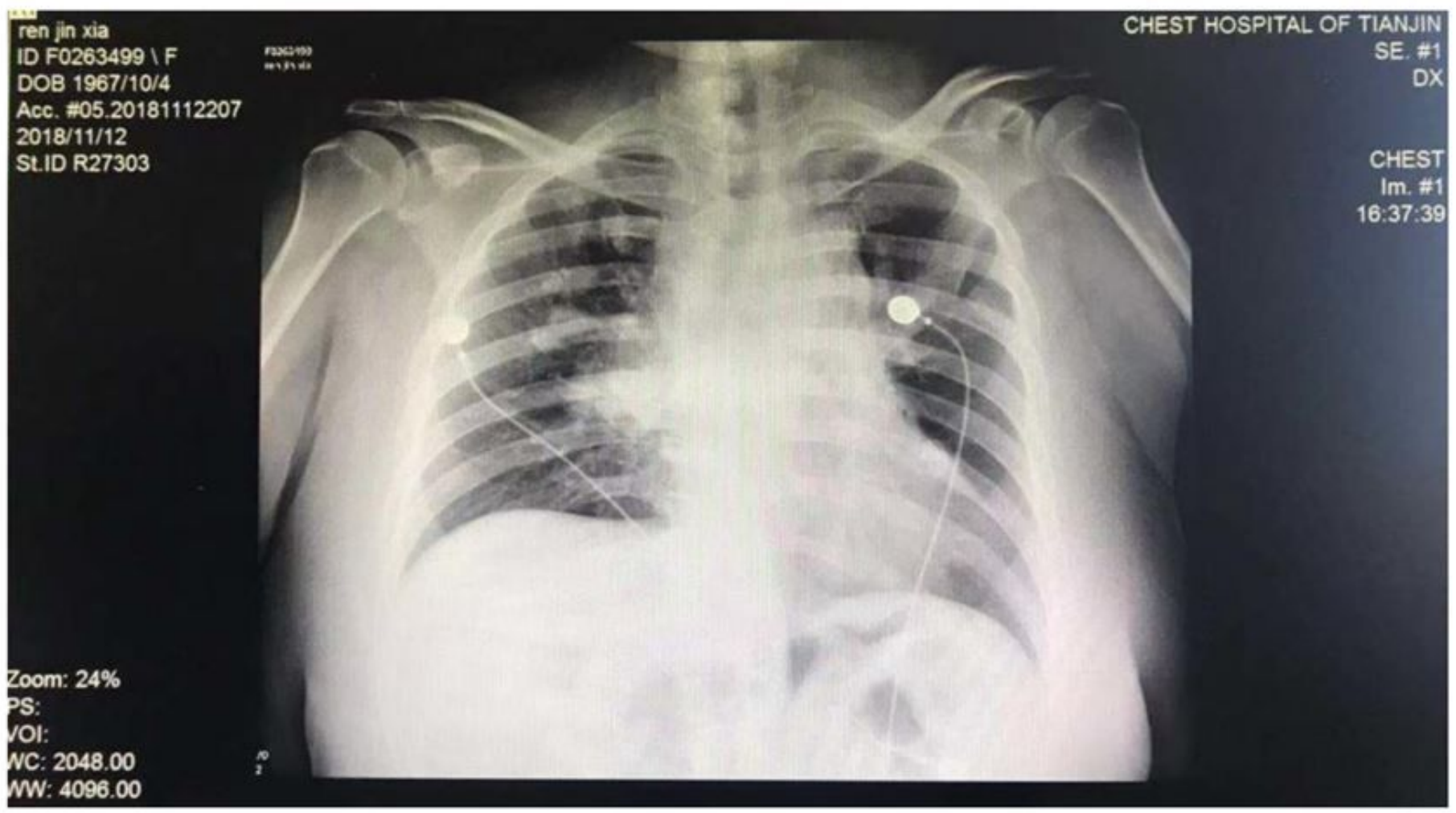

Figure 1

The chest X-ray of the current patient.
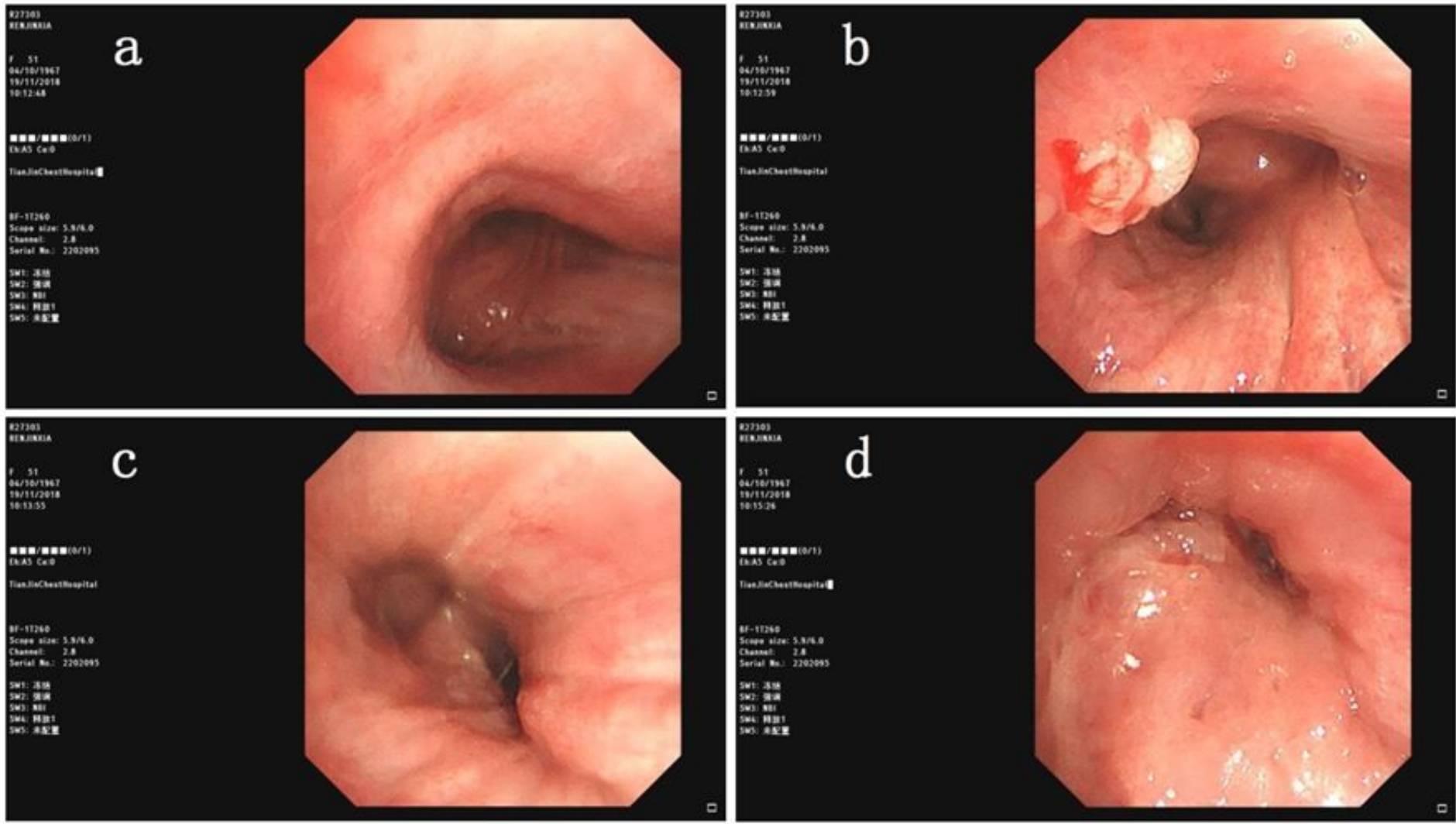

Figure 2 
Flexible bronchoscopy images of trachea (a), right main bronchus (b), right middle bronchus (c), left main bronchus (d).
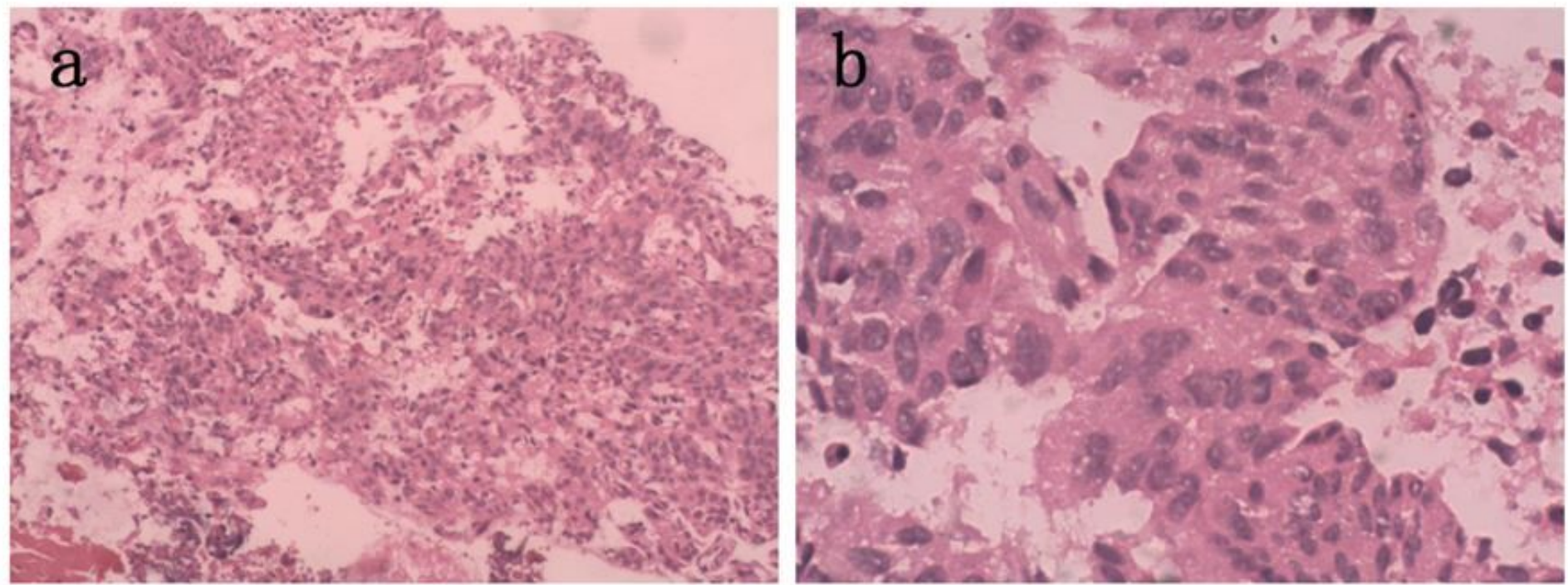

\section{Figure 3}

Hematoxylin-eosin (HE) staining of the neoplasm from the patient's bronchus. (a) Tumor cells arranged tightly and was irregular in shape. (magnification, $100 \times$ ). (b) Tumor cells and nucleus were not uniform in size and cells exhibited obvious atypia. (magnification, $400 \times$ ).
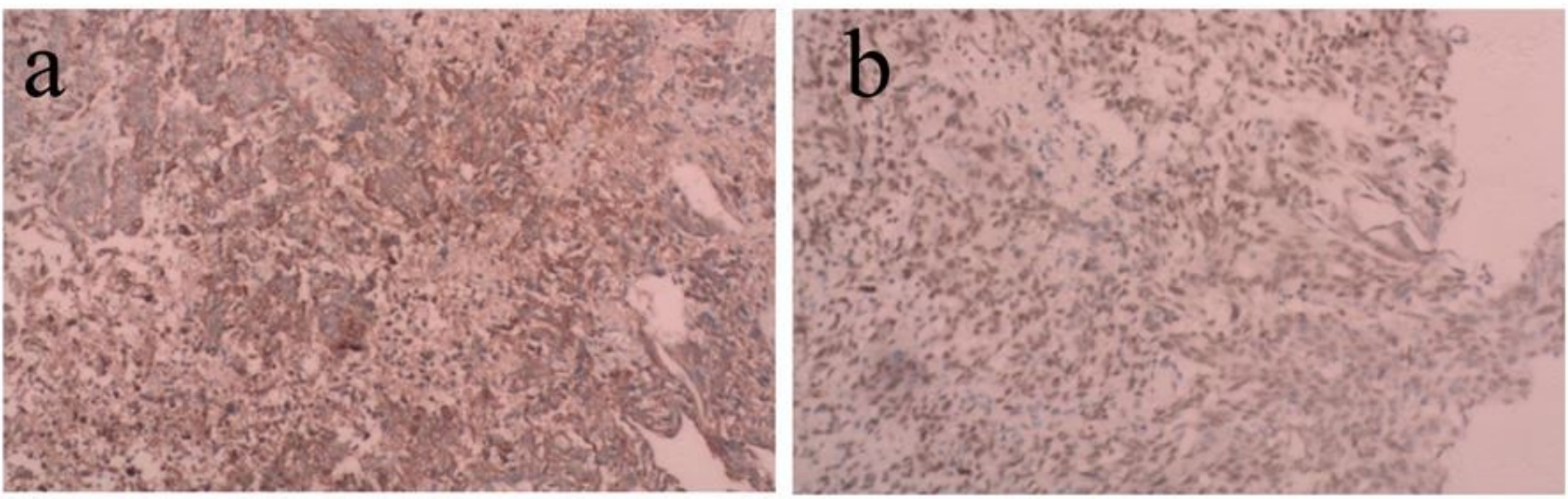

\section{Figure 4}

Immunohistochemistry (IHC) of the neoplasm from the patient's bronchus. (a) Staining with anti-CK antibody was positive, suggesting epithelial tumor. (magnification, $100 \times$ ). (b) Staining with anti-WT-1 antibody was positive, suggesting ovariogenic tumor. (magnification, $100 \times)$. 